\section{Zor Entübasyon Olgusunda Hava Yolu Ekstübasyon Kateterinin Yol Açtığı Pnömotoraks §}

\title{
Pneumothorax Caused by Airway Extubation Catheter in a Difficult Intubation Case
}

\author{
Kezban Aydan Okuyucu $\odot$ \\ Emine Yurt $\odot$ \\ Mehmet Yılmaz ๑ \\ Ayşe Adin Selçuk $\odot$ \\ Kemal Tolga Saraçoğlu ๑
}

Çıkar çatışması: Çalışmamızda yazarlar arasında çıkar çatış̧ması yoktur. Finansal destek: Makalemizde finansal destek alınmamıştır. Hasta onamı: Hastadan onam alınmıştır.
Conflict of interest: In our study, there is no conflict of interest among the authors.
Funding: No financial support was received in our article. Funding: No financial support was received in our article.
Informed consent: Consent was obtained from the patient.

Cite as: Okuyucu KA, Yurt E, Yılmaz M, Selçuk AA, Saraçoğlu KT. Zor entübasyon olgusunda havayolu ekstübasyon kateterinin yol açtığı pnömotoraks. GKDA Derg. 2020;26(2):106-10.

öz

Beklenen zor entubasyon olgularında uyanık fiber optik entübasyon ve tüp değiştirici kateter kullanılmaktadır. Bu uygulamalar yaşam kurtarıcı olmasının yanında bazı komplikasyonlara neden olabilir. Bu olguda, retromolar kitleye bağlı ağız açıklığı, 0,2 $\mathrm{mm}$ olan hastaya, biyopsi amaçlı uyanık nazal fiberoptik entubasyon yapıldı. Ekstubasyonda tüp değiştirici kateter kulanıldı. Ekstubasyon sonrası pnömotoraks gözlendi. Bu olguda, nazal uyanık fiberoptik entübasyon, tüp değiştirici kateterle yapılan ekstubasyon ve sonrasında gelişen pnömotoraks ile ilgili deneyimimizi sunduk.

Anahtar kelimeler: uyanık fiberoptik nazotrakeal entübasyon, tüp değiştirici kateter, pnömotoraks, zor hava yolu

\section{ABSTRACT}

In the expected cases of difficult intubation, awake fiberoptic nasotracheal intubation and tube-changing catheter are being used. These practices can be life-saving but can also induce some complications, as well. In this case report, a patient with a mouth opening of $0.2 \mathrm{~mm}$ due to retromolar mass underwent awake fiberoptic nasotracheal intubation for biopsy. A tube changer catheter was used on the extubation. Pneumothorax was observed after extubation. In this case, we present our experience with awake fiberoptic nasotracheal intubation, extubation performed with an airway exchange catheter in a patient who subsequently developed pneumothorax.

Keywords: awake fiberoptic nasotracheal intubation, airway exchange catheter, pneumothorax, difficult airway
Received: 26 August 2018 Accepted: 2 December 2019 Publication date: 30 June 2020

Kezban Aydan Okuyucu SBÜ Derince EAH Anestezi ve Reanimasyon Kliniğ 41400 Kocaeli - Türkiye - aydannn89@hotmail.com ORCID: 0000-0001-6338-8303

E. Yurt 0000-0003-3311-711X M. Yilmaz 0000-0002-5353-9996 SBÜ Kocaeli Derince EAH Anestezi ve Reanimasyon Kliniği Kocaeli - Türkiye

K. T. Saraçoğlu 0000-0001-9470-7418 SBÜ. Kartal Dr. Lütfi Kırdar EAH Anestezi ve Reanimasyon Kliniği Istanbul - Türkiye

A. A. Selçuk 0000-0002-3267-4638 SBÜ Kocaeli Derince EAH Kulak Burun Boğaz Kliniği Kocaeli - Türkiye

${ }^{\S} B u$ olgu sunumuna ait özet, 24. Türk Gögüus Kalp Damar Cerrahisi Anestezi Derneği Ulusal Kongresi'nde 3-6 Mayıs 2018'de sunulmuştur.

\section{Giriş}

Beklenen zor entübasyon olgularında American Society of Anesthesiologists (ASA) kılavuzunda önerilen yöntem uyanık entübasyon uygulamasıdır [1]. Fiber optik entübasyon hâlâ altın standart olmaya devam etmektedir. Uyanık entübasyon komplikasyonları arasında laringeal travma ve kanamaya bağlı olarak gelişen ödem, subglottik daralma ya da aşırı sedasyon ilk sıralarda yer almaktadır [2]. Difficult Airway Society (DAS) kılavuzunda zor entübe edilen hastaların ekstübasyonunda tüp değiştirici kateterlerin (airway extubation catheter; AEC) kullanılması önerilmektedir ${ }^{[3]}$. Ancak, bu kateterlerin kullanımı zor ekstübasyonda getirdiği yararlara rağmen, komp-

(C) Telif hakkı Göğüs Kalp Damar Anestezi ve Yoğun Bakım Derneği'ne aittir. Logos Tıp Yayıncılık tarafindan yayınlanmaktadır Bu dergide yayınlanan bütün makaleler Creative Commons Attf-Gayri Ticari 4.0 Uluslararası Lisansı ile lisanslanmıştır.

(c) Copyright The Society of Thoracic Cardio-Vascular Anaesthesia and Intensive Care. This journal published by Logos Medical Publishing. Licenced by Creative Commons Attribution-NonCommercial 4.0 International (CC BY-NC 4.0) 
likasyonsuz değildir. Bir çalışmada, 1177 olguluk bir seride \%13 oranında başarısızlık bildirilmiştir [4]. Bunların arasında \%7.8 hava yolu yaralanması, \%1,5 oranında pnömotoraks $(\mathrm{Px})$ yer almıştır. Bu makalede, literatür eşliğinde uyanık nazal fiber optik entübasyon, AEC ile yapılan ekstubasyon ve sonrasında gelişen Px olgusunu tartıştık.

\section{OLGU}

Otuz sekiz yaşında, hipertansiyon tanılı kadın hasta, retromolar kitle nedeniyle KBB kliniğine başvurmuştu. Özgeçmişinde apendektomi ve hemoroidektomi ameliyatları vardı. Skuamöz hücreli karsinom nedeniyle 5 kür kemoterapi ve radyoterapi alan ve ağız açıklığı $0.2 \mathrm{~mm}$ olan hastaya retrofaringeal biyopsi planlandı (Resim 1'e bakınız). Baş-boyun muayenesi sonucu hastanın hava yolu "beklenen zor entübasyon" olarak değerlendirildi. Baş-boyun malignitesi olan olgular için spesifik hava yolu değerlendirme kriterleri esas alındı ve hastaya uyanık nazal fiber optik entübasyon planlandı ${ }^{[5]}$. Hastadan onam alındı.

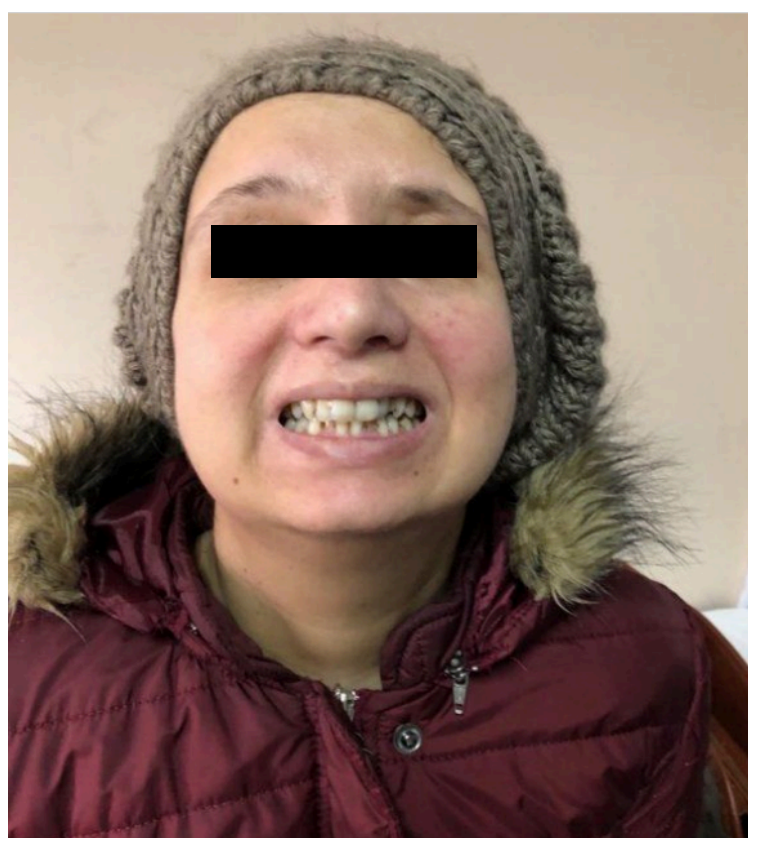

Resim 1. Hastanın preoperatif üst havayolunun muayenesi.
$60 \mathrm{mg}$ lidokain inhaler yolla verildi, nazal topikal anestezi yapıldı. Preoksijenasyon için yüksek akımlı nazal oksijen sistemi (POINT) aracılığıyla \%100 oksijen, titre edilerek akım 50 L/dk.'ya kadar artırıldı, uyanık entübasyon sırasında yüksek akıma devam edildi. Semifowler pozisyona alınan hastaya $0.1 \mathrm{mcg} /$ kg/dk. hızında i.v. remifentanil infüzyonu başlandı.

Spontan solunum korunarak nazotrakeal entübasyon $1 \mathrm{dk}$. içinde komplikasyonsuz olarak gerçekleştirildi (Resim 2'e bakınız). Ardından uygun cerrahi koşulları

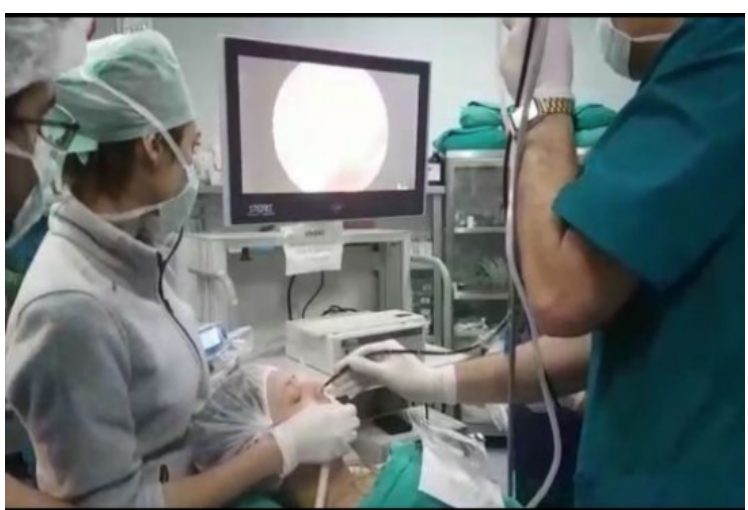

Resim 2. Başarılı uyanık nazal fiberoptik entübasyon.

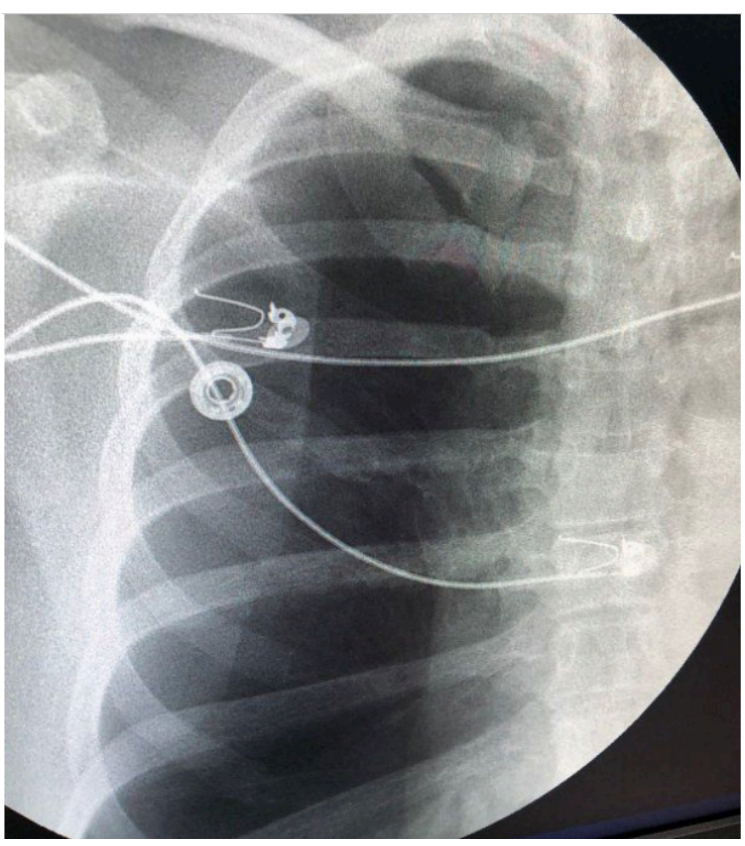

Resim 3. Postoperatif gelişen sağ pnömotoraksın PA akciğer filminde görüntülenmesi. 
sağlamak için $2 \mathrm{mg} / \mathrm{kg}$ propofol, $0,5 \mathrm{mg} / \mathrm{kg}$ rokuronyum uygulandı. Anestezi idamesi $\% 50 \mathrm{O}_{2}$-hava karışı$\mathrm{m}$ içinde $2 \%$ sevofluran ile sürdürüldü. Altmış dk. süren cerrahinin sonunda spontan solunumu dönen hastaya trakeal tüp çekilmeden önce endotrakeal tüp içerisinden AEC yerleştirildi. Genel durumu stabil olan hasta ekstübe edildi. Ekstübasyondan bir süre sonra subksifoid göğüs ağrısından yakınan hastanın dinlemekle sağda solunum sesleri azalmıştı ve bilateral servikal subkutan amfizemi bulunmaktaydı. Başlangıçta servikal bölgede olan subkutan amfizem dakikalar içinde torakal ve abdominal bölgeye kadar yayılmıştı. PA akciğer filmi çekilen hastaya sağ pnömotoraks tanısıyla toraks tüpü takıldı (Resim 3'e bakınız). Hasta gözlem amaçı 1 gün KBB servisinde takip edildi, ardından ek komplikasyon gelişmeyen taburcu edildi.

\section{TARTIŞMA}

Hastada gelişen pnömotoraksın ayırıcı tanısında uygulanan cerrahi işlem, ekstübasyon kateterine bağlı travma ve Px olarak değerlendirildi. Gözlemlerimiz sırasında kontrolsüz bir zor trakeal entübasyon gelişmediğinden, ayrıca ekstübasyon kateterinden basınçlı ventilasyon uygulanmadığından hasta spontan Px olarak değerlendirildi. Büllöz akciğer bakımından ileri değerlendirme amaçlı göğüs hastalıkları kliniğine yönlendirildi.

AEC insuflasyon ile manuel ventilasyona ve jet ventilasyona olanak sağlamakta, aynı zamanda reentübasyon olasılığı yüksek olan hastalarda stile olarak kullanılabilmektedir. Özellikle cerrahi yoğun bakım ünitelerinde \%19 reentübasyon olasıllığı olduğu düşünüldüğünde, AEC değerli ve güvenli bir hava yolu aygıtı olarak klinikte kullanım alanı bulmuştur $[5-8,10,17]$.

Uyanık fiber optik entübasyonda görülebilen komplikasyonlar yüksek akım oksijene bağlı gastrik insuflasyon, organ rüptürü ve barotravmadır ${ }^{[9,10]}$. AEC uygulanması sırasında gelişebilecek komplikasyonlar yanIış yere uygulama, larinks, bronş veya akciğerin direk hasarı, oksijen suplementasyonuna bağlı barotravma ve hava yolu açıklığının kaybıdır. Trakeobronşiyal anatomi göz önüne alındığında AEC'in aşırı ilerletilmesiyle sıklıkla sağ ana bronşta hasar oluşabilmektedir. Bu durum da sağ hemitoraksta Px olarak kliniğe yansıyabilmektedir. Pnömomediastinum, pnömoperitoneum ve hatta ölümle sonuçlanan olgular da bildirilmiştir ${ }^{[11,12] .}$

Hastamızda AEC kateteri güvenli ekstubasyon amaçlı yerleştirilmiştir. Bu sırada gelişen bir barotravma da pnömotoraksa yol açabilir. Barotravma riski nedeniyle, özellikle yüksek akımlı oksijen desteği yapılan hastalarda yeterli ekspiryumun sağlandığı doğrulanmalıdır ${ }^{[13]}$. Alternatif olarak yumuşak uçlu olan ekstubasyon kılavuz teli bu olguda kullanabilirdik, ancak bunun da mukozal hasar yapabildiği gösterilmiştir ${ }^{[14]}$.

Benzer şekilde, yüksek frekanslı jet ventilasyon yapılmadan AEC kullanımında Px bir komplikasyon olarak bildirilmiştir ${ }^{[15]}$. AEC kullanımında pnömotoraks gelişiminin 2 asıl mekanizması olduğu düşünülmüştür. Birincisi trakeobronşiyal ağacın kateterle mekanik travması sonucu mukozal hasara neden olabilir. Bu mekanizmayla gelişen fatal pnömotoraks bildirilmiştir ${ }^{[15,16]}$. İkinci mekanizma ise jet ventilasyona bağ|ı barotravmadır. Dinamik hiperinflasyon, oto PEEP oluşumu sonucu barotravma ve buna bağlı olarak pnömotoraks, pnömomediastinum ve subkutan amfizem gelişebilmektedir ${ }^{[17,18]}$. Olgumuzda gelişen dinamik hiperinsuflasyonun oto PEEP ile sonuçlanarak barotravmaya yol açtığı düşünülmüştür. Ayrıca subkutan amfizem de gelişsmiş, tedavisi planlanmıştır.

AEC kullanımında klinisyenler genellikle barotravmanın önlenmesine dikkat etsede, yerleştirme tekniği de yaşamı tehdit edici komplikasyonların önlenmesi için büyük öneme sahiptir. Erişkin hastalarda kateter $26 \mathrm{~cm}$ 'den fazla ilerletilmemeli ve direnç hissedildiğinde zorlanmamalıdır. AEC yerleştirilmesine bağı oluşan trakeobronşiyal ağaç hasarı gerçekleşen 2 farklı olguda da yırtılma karinanın aşağısında gözlenmiştir ${ }^{[19,20]}$. Olguda kateter $25 \mathrm{~cm}$ 'den fazla ilerletilmediği için spontan Px düşünülmüştür. 
Literatürde uyanık fiber optik entübasyon sırasında gelişebilecek birçok komplikasyon olmakla beraber, olgumuzda entübasyonda herhangi bir olumsuzluk yaşanmamıştır. Bin altı yüz on iki hastanın olduğu bir çalışmada, nazotrakeal entübasyon olgularının \%1.3'ünde majör komplikasyon olarak ciddi nazal kanama gözlenmiştir ${ }^{[21]}$. Uyanık nazotrakeal entübasyon \%1.8 olguda başarısız olmuştur. Başka bir çalışmadaysa uyanık entübasyonda başarısızlık oranı \%1, komplikasyon oranı \%1.6 olarak saptanmıştır ${ }^{[22]}$.

\section{SONUÇ}

Gözlemlerimiz sırasında kontrolsüz bir zor trakeal entübasyon gelişmediğinden ayrıca ekstübasyon kateterinden basınçı ventilasyon uygulanmadığından hasta spontan pnömotoraks olarak değerlendirildi.

Sonuç olarak, beklenen zor entübasyonda altın standart uyanık fiber optik entübasyondur. Zor entübasyon sonrası ekstübasyonun planlanmasında AEC kullanımı önerilen uygulamadır. AEC güvenli ekstübasyona olanak sağlamaktadır, ancak pnömotoraks, pnömomediastinum ve subkutan amfizem gibi komplikasyonların olabileceği de anımsanmalıdır.

\section{KAYNAKLAR}

1. Practice guidelines for management of the difficult airway: an updated report by the American Society of Anesthesiologists Task Force on Management of the Difficult Airway.

2. El-Boghdadly K, Onwochei DN, Cuddihy J, Ahmad I. A prospective cohort study of awake fibreoptic intubation practice at a tertiary centre. Anaesthesia 2017;72: 694-703. https://doi.org/10.1111/anae.13844

3. https://www.das.uk.com/content/das-extubationguidelines

4. McLean S, Lanam CR, Benedict W, Kirkpatrick N, Kheterpal S, Ramachandran SK. Airway Exchange failure and complications with the use of the Cook Airway Exchange Catheter ${ }^{\circledR}$ : a single center cohort study of 1177 patients. Anesth Analg. 2013;117:1325-7. https://doi.org/10.1213/ANE.0b013e3182a7cd3d

5. Supkis DE Jr, Dougherty TB, Nguyen DT, Cagle CK.
Anesthetic management of the patient undergoing head and neck cancer surgery. Int Anesthesiol Clin. 1998;36:21-9.

https://doi.org/10.1097/00004311-199803630-00005

6. Benumof JL. Airway exchange catheters: simple concept, potentially great danger. Anesthesiology. 1999;91: 342-4. https://doi.org/10.1097/00000542-199908000-00005

7. Saracoglu KT, Yilmaz M, Duzyol IY, Turan AZ, Okuyucu KA, Yurt E. Advanced techniques in extubation: Bailey maneuver, tube exchange catheter and staged extubation set. J Clin Anesth. 2018;48:28-9. https://doi.org/10.1016/j.jclinane.2018.04.019

8. Demling RH, Read T, Lind LJ, Flanagan HL: Incidence and morbiditiy of extubation failure in surgical intensive care patients. Crit Care Med. 1988;16:573-7. https://doi.org/10.1097/00003246-198806000-00001

9. Ho CM, Yin IW, Tsou KF, Chow LH, Tsai SK. Gastric rupture after awake fibreoptic intubation in a patient with laryngeal carcinoma. Br J Anaesth. 2005;94:856-8. https://doi.org/10.1093/bja/aei124

10. Pirlich N, Lohse JA, Noppens RR. Topical Airway Anesthesia for Awake-endoscopic Intubation Using the Spray-as-you-go Technique with High Oxygen Flow. J Vis Exp 2017 Jan 13;(119). https://doi.org/10.3791/55116

11. Baraka AS. Tension pneumothorax complicating jet ventilation via a cook airway exchange catheter. Anesthesiology. 1999 Aug;91(2):557-8. https://doi.org/10.1097/00000542-199908000-00031

12. de Almeida JP, Hajjar LA, Fukushima JT, Nakamura RE, Albertini R, Galas FR. Bronchial injury and pneumothorax after reintubation using an airway exchange catheter. Braz J Anesthesiol. 2013;63:107-9. https://doi.org/10.1016/S0034-7094(13)70202-2

13. Hulst AH, Avis HJ, Hollmann MW, Stevens MF. Massive Subcutaneous Emphysema and Bilateral Tension Pneumothoraces After Supplemental Oxygen Delivery via an Airway Exchange Catheter: A Case Report. A A Case Rep. 2017;8:26-8. https://doi.org/10.1213/XAA.0000000000000414

14. Axe R, Middleditch A, Kelly FE, Batchelor TJ, Cook TM. Macroscopic barotrauma caused by stiff and softtipped airway exchange catheters: an in vitro case series. Anesth Analg. 2015;120:355-61. https://doi.org/10.1213/ANE.0000000000000569

15. Duggan LV, Law JA, Murphy MF. Brief review: Supplementing oxygen through an airway exchange catheter: efficacy, complications, and recommendations. Can J Anaesth. 2011;58:560-8. https://doi.org/10.1007/s12630-011-9488-4

16. Rashid AM, Williams C, Noble J, Rashid OM, Takabe K, Anand RJ. Pneumothorax, an underappreciated comp- 
lication with an airway exchange catheter. J Thorac Dis 2012;4:659-62.

17. Harris K, Chalhoub M, Maroun R, Elsayegh D. K. A. Okuyucu ve ark., Zor Entübasyon Olgusunda Hava Yolu Ekstübasyon Kateterinin Yol Açtığı Pnömotoraks Endotracheal tube exchangers: should we look for safer alternatives? Heart Lung 2012;41:67-9. https://doi.org/10.1016/j.hrtlng.2011.06.005

18. Nunn C, Uffman J, Bhananker SM. Bilateral tension pneumothoraces following jet ventilation via an airway exchange catheter. J Anesth. 2007;21:76-9. https://doi.org/10.1007/s00540-006-0463-0

19. DeLima LG, Bishop MJ. Lung laceration after tracheal extubation over a plastic tube changer. Anesth Analg. 1991;73:350-1. https://doi.org/10.1213/00000539-199109000-00022

20. Seitz PA, Gravenstein N. Endobronchial rupture from endotracheal reintubation with an endotracheal tube guide. J Clin Anesth. 1989;1:214-7. https://doi.org/10.1016/0952-8180(89)90044-5

21. Heidegger T, Gerig HJ, Ulrich B, Schnider TW. Structure and process quality illustrated by fibreoptic intubation: analysis of 1612 cases. Anaesthesia. 2003;58:734-9. https://doi.org/10.1046/j.1365-2044.2003.03200.x

22. Joseph TT, Gal JS, DeMaria S Jr, Lin HM, Levine Al, Hyman JB. A retrospective study of success, failure, and time needed to perform awake intubation. Anesthesiology 2016;125:105-14. https://doi.org/10.1097/ALN.0000000000001140 